\title{
A IMPORTÂNCIA DO MAPEAMENTO DE PROCESSOS PARA O ENSINO E APRENDIZAGEM DOS ALUNOS DO CURSO TECNICO EM ADMINISTRAÇÃO DO IFBAIANO
}

\author{
Rosana Rocha Siqueira, IFBAIANO \\ hosanalilas393@yahoo.com.br \\ Anabel Santos Ribeiro, IFBAIANO \\ anabel.sribeiro@outlook.com \\ Gabrielly Rodrigues Chaves, IFBAIANO \\ gabby1315s@gmail.com \\ Gustavo Gomes Apostolo, IFBAIANO \\ gustavoapostolo2002@gmail.com \\ Julia Serra Bastos, IFBAIANO \\ juliasbs217@gmail.com \\ Luiz Paulo Fagundes, IFBAIANO \\ luizpaulofagundes@ hotmail.com \\ Naira Morais Pereira, IFBAIANO \\ nairamoraes@gmail.com \\ Natany Gaspari Soares, IFBAIANO \\ natanygaspari@gmail.com
}

\section{RESUMO}

Considera-se que o conhecimento dos processos organizacionais e suas variáveis internas e externas influenciam diretamente no alcance dos objetivos, além de oferecer respostas adequadas aos órgãos de controle, indicando segurança aos atos da gestão. Neste contexto esta pesquisa de caráter qualitativo tem como objetivo central o estudo dos processos do setor refeitório do Campus do IFBAIANO em Teixeira de Freitas/BA. Como resultados pode-se de formular fluxogramas, colaborando para $\mathrm{O}$ desenvolvimento institucional, Governança Corporativa e possível melhoria dos serviços. Neste sentido a colaboração dos discentes do Curso Técnico Integrado em Administração configura-se como prática importante para a rotina dos futuros técnicos em Administração e para as organizações em que estarão inseridos no mercado de trabalho.

Palavras-Chave: Processos, Mapeamento, Administração.

Data de recebimento: 03/05//2020

Data do aceite de publicação: 25/11/2020

Data da publicação: $30 / 12 / 2020$ 


\title{
A IMPORTÂNCIA DO MAPEAMENTO DE PROCESSOS PARA O ENSINO E APRENDIZAGEM DOS ALUNOS DO CURSO TÉCNICO EM ADMINISTRAÇÃO DO IFBAIANO
}

\section{THE IMPORTANCE OF PROCESS MAPPING FOR TEACHING AND LEARNING TECHNICAL STUDENTS IN ADMINISTRATION IN IFBAIANO}

\author{
Rosana Rocha Siqueira, IFBAIANO \\ hosanalilas393@yahoo.com.br \\ Anabel Santos Ribeiro, IFBAIANO \\ anabel.sribeiro@outlook.com \\ Gabrielly Rodrigues Chaves, IFBAIANO \\ gabby1315s@gmail.com \\ Gustavo Gomes Apostolo, IFBAIANO \\ gustavoapostolo2002@gmail.com \\ Julia Serra Bastos, IFBAIANO \\ juliasbs217@gmail.com \\ Luiz Paulo Fagundes, IFBAIANO \\ luizpaulofagundes@hotmail.com \\ Naira Morais Pereira, IFBAIANO \\ nairamoraes@gmail.com \\ Natany Gaspari Soares, IFBAIANO \\ natanygaspar@gmail.com
}

\begin{abstract}
It is considered that the knowledge of the organizational processes and their internal and external variables directly influence the achievement of the objectives, in addition to offering adequate responses to the control bodies, indicating security to the management acts. In this context, this qualitative research has as main objective the study of the processes of the cafeteria sector of the IFBAIANO Campus in Teixeira de Freitas / BA. As a result, flow charts can be formulated, contributing to institutional development, Corporate Governance and possible improvement of services. In this sense, the collaboration of the students of the Integrated Technical Course in Administration is an important practice for the routine of future technicians in Administration and for the organizations in which they will be inserted in the labor market.
\end{abstract}

Keywords: Process, Mapping, Administration.

\section{INTRODUÇÃO}

A incerteza e o risco fazem parte do dia a dia das pessoas e das organizações em que estão inseridas, visto que diversas variáveis socioeconômicas, legais, tecnológicas e ambientais podem interferir de força positiva ou negativa em suas atividades, assim "[...] a incerteza o risco encontram-se presentes em todos os aspectos cotidianos da vida, de maneira que o estudo desses aspectos devem permitir que as decisões sejam tomadas de maneira mais realística" (MENEZES, 2011, p.59).

Para Dubrin (2003, p.83) uma condição de certeza parte de fatos e resultados conhecidos e previsíveis, já o risco envolve "certeza incompleta com relação aos resultados de vários cursos de ação alternativos". Em relação a incerteza o autor indica a necessidade de decidir tomando-se como base informações limitadas que possam criar dúvidas. Segundo a Norma ABNT NBR ISO 31000 (2009, p.1) "a incerteza é o estado, mesmo que parcial, da deficiência das informações relacionadas a um evento, sua 


\section{A IMPORTÂNCIA DO MAPEAMENTO DE PROCESSOS PARA O ENSINO E APRENDIZAGEM DOS ALUNOS DO CURSO TECNICO EM ADMINISTRAÇÃO DO \\ IFBAIANO}

compreensão, seu conhecimento, sua consequência ou sua probabilidade".

Diante disso, segundo informações do Tribunal de Contas da União (TCU, BRASIL, 2018, p.01) a gestão de riscos ainda é considerada um desafio no cotidiano das organizações públicas visto que "persiste a necessidade não apenas de estruturas e processos, mas também de uma cultura de gerenciamento de riscos, a fim de contribuir para que a organização obtenha resultados com desempenho otimizado.

Assim, a ampliação dos estudos e a prática do gerenciamento de riscos é importante não só aos servidores públicos, mas também aos estudantes que futuramente poderão ocupar cargos no mercado de trabalho, uma vez que "[...] as atividades de qualquer organização envolvem riscos que, se não gerenciados adequadamente, poderão se materializar e comprometer sua capacidade de gerar, preservar ou entregar valor. (TCU, BRASIL, 2018, p.02).

Esta temática alinhada ao mapeamento de processos torna-se importante para o ensino e aprendizagem dos alunos do Curso Técnico em Administração do IFBAIANO, uma vez que contextualiza a vivência dos discentes conectando-a com ferramentas e conteúdos explanados durante o curso.

Desta forma, o presente artigo basea-se em pesquisas e trabalhos de campo realizados durante o ano letivo de 2019 no Instituto Federal de Educação, Ciência e Tecnologia Baiano (IFBAIANO), Campus Teixeira de Freitas, localizado no Extremo Sul do Estado da Bahia.

Anualmente no transcorrer da disciplina Projeto Integrador as turmas do Curso Integrado em Administração desenvolvem pesquisas com diversos enfoques. A depender da temática, das variáveis e condições envolvidas pode-se inclusive optar por projetos de intervenção com resultados práticos. Neste contexto propoem-se como objetivo da disciplina:

Aplicar, de forma contextualizada e participativa, os conteúdos abordados durante o período. Trabalhar com a construção interdisciplinar do conhecimento, buscando, continuadamente, a autonomia do estudante. BRASIL IFBAIANO. Disponivel em: $<$ https://www.ifbaiano.edu.br/unidades/teixeira/files/2018/04/PP C-Curso-Tecnico-Integrado-

Administra\%C3\%A7\%C3\%A3o.pdf>.Acesso em: 05 de abr. 2020 .

O percurso da pesquisa que fundamenta o projeto integrador parte da premissa interdisciplinar com aporte de conteúdos de metodologia científica e demais disciplinas que convergem para o tema central do projeto e sua problemática.

Dessa forma, os discentes divididos em equipes podem se debruçar sobre problemáticas do seu cotidiano dialogando assim com ferramentas e conteúdos explanados em sala de aula, orientados por um ou mais docentes, que ao final do ano letivo avaliam o trabalho desenvolvido.

O "lugar de fala" da equipe deste estudo remete a vivência dos discentes como usuários do setor refeitório uma vez que são discentes da instituição e também pesquisadores participantes.

Para isso, a pesquisa teve como objetivo central o estudo dos processos do setor refeitório do Campus Teixeira de Freitas com o intuito de formular fluxogramas, colaborando para o desenvolvimento institucional e possível melhoria dos serviços. Lage Júnior (2016,p.48) salienta que “o mapeamento é considerado apenas a 


\section{A IMPORTÂNCIA DO MAPEAMENTO DE PROCESSOS PARA O ENSINO E APRENDIZAGEM DOS ALUNOS DO CURSO TÉCNICO EM ADMINISTRAÇÃO DO IFBAIANO}

representação de processos já existentes", dos quais apartir desta apresentação pode ser possível a proposição de adequações e melhorias

A escolha do tema levou em consideração também a dificuldade dos discentes no tocante a "visualização" dos processos e tarefas de uma organização e a importância do mapeamento de processos para a clareza, eficácia e eficiência dos objetivos a que se propõem, algo essencial para que se possa administrar pautado em pressuposto de governança corporativa. Neste sentido a governância corporativa "insere-se em conjunto de ações que auxiliam no processo decisório dos gestores em busca de solucionar problemas ou maximizar oportunidades, com foco no bem-estar da sociedade e no interesse público" (BRASIL,TCU, 2018, n.p).

A governança corporativa nas organizações brasileiras e a busca por práticas de melhoria contínua são grandes desafios em cenários de contingências. Pode ser considerada como "como um conjunto de mecanismos de liderança, estratégia e controle postos em prática para avaliar, direcionar e monitorar a gestão, com vistas à condução de políticas públicas e à prestação de serviços de interesse da sociedade" (BRASIL,TCU, 2014, p.05).

Neste contexto, o famoso "jeitinho brasileiro" impera como qualidade e valorização de soluções improvisadas, denominada erroneamente como "criatividade" e pode inibir a adoção de procedimentos adequados nos processos, que ao invés de pautarem-se em planejamento prévio passam a ocorrer de forma arriscada e reativa frente às incertezas. Neste tocante o magistrado e Ministro do Supremo Tribunal Federal Luís Roberto Barroso comenta sobre vertente do "jeitinho brasileiro":

$\mathrm{Na}$ vertente negativa, a ideia de jeitinho congrega características que não são edificantes. Sem nenhuma intenção de hierarquizálas, começo pelo improviso, a incapacidade de planejar, de cumprir prazos e, em última análise, de cumprir a palavra. Vivese aqui a crença equivocada de que tudo se ajeitará na última hora, com um sorriso, um gatilho e a atribuição de culpa a alguma fatalidade (falsamente) inevitável, e não à imprevidência. (BARROSO, 2017, p.06).

Principalmente na esfera pública "é importante garantir o comportamento ético, íntegro, responsável, comprometido e transparente da liderança [...]" (TCU, 2014, p.13). Isso mostra que gerir uma instituição pública, é uma tarefa que exige compromisso para administrar de forma coerente todos os setores da unidade, estando sempre de acordo com os propostos do Referencial Básico de Governança do Tribunal de Contas da União. Assim, para seguir essa conduta é preciso:

[...] observar e garantir a aderência das organizações às regulamentações, códigos, normas e padrões; garantir a transparência e a efetividade das comunicações; balancear interesses e envolver efetivamente os stakeholders (cidadãos, usuários de serviços, acionistas, iniciativa privada). (BRASIL, TCU, 2014, p.13).

Neste contexto a equipe de pesquisa acessou documentos norteadores da Política de Governança e Gestão de Riscos do Governo Federal e do IFBAIANO, Regimentos Internos do Campus Teixeira de Freitas e da Coordenação de Assistência Estudantil 


\section{A IMPORTÂNCIA DO MAPEAMENTO DE PROCESSOS PARA O ENSINO E APRENDIZAGEM DOS ALUNOS DO CURSO TECNICO EM ADMINISTRAÇÃO DO IFBAIANO}

(CAE) do campus que institui os processos que regem o setor refeitório e demais documentos relacionados a temática.

\section{MAPEAMENTO DE PROCESSOS}

O mapeamento de processos é uma ferramenta de gestão que está diretamente voltada ao entendimento de processos de negócios voltada a possíveis melhorias e implantações de novos processos (ALMEIDA, 2016, n.p.).

Quanto aos fluxogramas trata-se de uma representação gráfica que expõe os passos e etapas de determinado processo. Segundo Alonço (2017,n.p):

Por meio de figuras geométricas e outros elementos similares, um fluxograma quando bem elaborado consegue simplificar o fluxo de informações, o fluxo das atividades e entre outros elementos que compõem cada tipo de processo em uma organização.

Desse modo, por meio do uso de alguns símbolos, o fluxograma revela passo a passo as etapas das atividades que juntas formam os processos, estabelecendo um fluxo com início, meio e fim.

Neste sentido, Baum (2015, n.p.) considera como macroprocesso "o meio pelo qual a organização reúne os grandes conjuntos de atividades para gerar valor e cumprir a sua missão. Dentro do macroprocesso estão as funções de organização". Conforme Ribeiro et al (2010, p. 4) "os processos são constituídos de atividades e tarefas que consomem recursos e criam bens e serviços para os clientes".

Quanto a atividade, Ribeiro et al (2010, p. 4) classifica como:

[...] uma ação que utiliza recursos humanos, materiais, financeiros e tecnologia para a produção de bens e serviços. É composta por um conjunto de tarefas necessárias ao seu desempenho. As atividades são necessárias para a concretização de um processo, que é uma cadeia de atividades interrelacionadas. As tarefas são as menores partes de uma atividade, são ações/movimentos específicos que contribuem para um resultado. Inúmeras tarefas podem fazer parte de uma atividade.

Segundo Alonço (2017,n.p):

O fluxograma de processos linear é um diagrama que exibe a sequência de trabalho com o acréscimo dos pontos de decisão durante o fluxo. Sua abrangência pode auxiliar os processos na identificação de gargalos, retrabalho e redundâncias nos processos.

Para o andamento inicial do estudo vale ressaltar que a equipe de pesquisa teve acesso através do Núcleo de Planejamento e Parcerias Institucionais (NUPPI) do Campus Teixeira de Freitas a uma listagem prévia das atividades realizadas pela 


\section{A IMPORTÂNCIA DO MAPEAMENTO DE PROCESSOS PARA O ENSINO E APRENDIZAGEM DOS ALUNOS DO CURSO TÉCNICO EM ADMINISTRAÇÃO DO IFBAIANO}

nutricionista relativas aos processos do setor refeitório.

Desta forma a intervenção da equipe de pesquisa enquadrou-se no seguinte âmbito:

Figura 01- Esquema criado pelo NUPPI do Campus Teixeira de Freitas/BA.
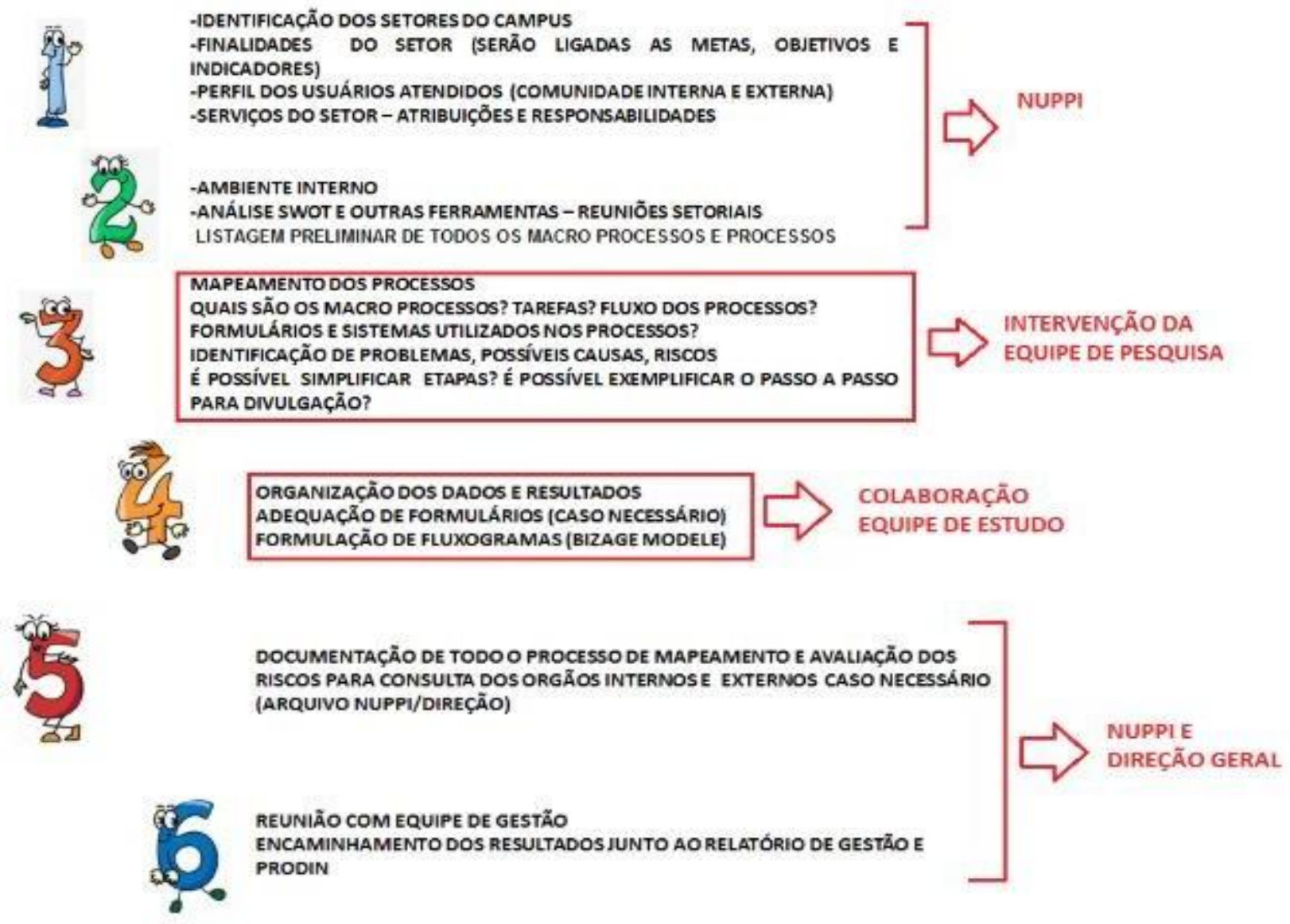

Fonte: Siqueira/NUPPI, 2019.

Destaca-se desta forma como produto da intervenção a entrega dos fluxogramas como os processos mapeados do setor refeitório, bem como possíveis sugestões de melhorias para o setor.

\subsection{Gestão de risco}

A Norma ABNT NBR ISO 31000 (2009, p.1) indicam em suas notas 3 e 4 que o risco é caracterizado "pela referência aos eventos" ou "uma combinação de consequências de um evento (incluindo mudanças nas circunstâncias) e a probabilidade de ocorrência associada".

Segundo o Art. $9^{\circ}$ da Seção I, Cap. II da Política de Gestão de Riscos para Órgãos e Entidades - IFBAIANO (2018, p.3)

São objetivos da gestão de riscos: 


\section{A IMPORTÂNCIA DO MAPEAMENTO DE PROCESSOS PARA O ENSINO E APRENDIZAGEM DOS ALUNOS DO CURSO TECNICO EM ADMINISTRAÇÃO DO IFBAIANO}

I - assegurar que todas as partes interessadas de um processo, em todos os níveis, tenham acesso tempestivo a informações suficientes quanto aos riscos aos quais está exposta a organização, inclusive para determinar questões relativas à delegação, se for o caso;

II - aumentar a probabilidade de alcance dos objetivos da organização, reduzindo os riscos a níveis aceitáveis;

III - agregar valor à organização por meio da melhoria dos processos de trabalho de decisão e do tratamento adequado dos riscos e dos impactos decorrentes de sua materialização.

As medidas acima traçadas contribuem não só para o alinhamento de planos estratégicos como também para a integração das atividades organizacionais e processos da tomada de decisões, o que incentiva um maior comprometimento por parte do gestor.

Pressupõe que o sistema de gestão de riscos e controle interno seja monitorado e avaliado pela mais alta instância interna de governança da organização, considerando aspectos como conformidade legal e regulamentar, aderência a boas práticas, alinhamento a estratégias da organização e desempenho global. Como resultado do monitoramento e avaliação, medidas visando o aprimoramento do sistema são implementadas sempre que necessário. (TCU, 2014, p. 57).

Para tanto, a Política citada assume em suas premissas alguns conceitos que facilitam a compreensão da natureza dos riscos, para que assim sejam criados métodos com o objetivo de tratá-los de forma coerente.

Neste contexto o Comitê Técnico de Riscos do Ministério Público (ENAP, 2018, p.13) dispõem as categorias de risco da seguinte forma:

I - Estratégico: corresponde àquelas que apresentam impactos no processamento dos objetivos, missão ou metas traçadas pela empresa.

II - Operacional: abrange eventos que podem causar transtorno nas atividades da unidade, como falhas ou a inadequação de processos, prejudicando assim a eficácia e eficiência dos procedimentos organizacionais.

III - Orçamentário: eventos com potencial de comprometer recursos orçamentários das atividades, ou até mesmo comprometer a própria execução orçamentária. Um exemplo desse tipo é o atraso no cronograma de licitações.

IV - Reputação: está relacionada aos eventos que prejudicam a imagem e relação da organização com a sociedade, infringindo a capacidade da instituição de cumprir a sua missão.

V - Integridade: corresponde a eventos que afetam a dignidade da empresa, o que prejudica a gestão de recursos públicos e atividades organizacionais.

VII - Fiscal: eventos que causam impacto negativo no equilíbrio das contas públicas.

VIII - Conformidade: eventos que interferem no cumprimento de leis e regulamentos.

Além da categorização dos eventos, são realizadas avaliações a respeito da mensuração e apetite ao risco, que significam respetivamente a estimativa do impacto 


\section{A IMPORTÂNCIA DO MAPEAMENTO DE PROCESSOS PARA O ENSINO E APRENDIZAGEM DOS ALUNOS DO CURSO TÉCNICO EM ADMINISTRAÇÃO DO IFBAIANO}

ocasionado e o nível de risco no qual a organização está disposta a operar. Segundo Pardini (2017, n.p) "a alta gestão tem como responsabilidade definir o apetite ao risco, além de supervisionar para que este apetite seja base para a definição da estratégia da organização".

Com intuito de estabelecer medidas para geri-lo de forma adequada, os riscos podem ser classificados como inerentes ou residuais. $\mathrm{O}$ risco inerente acontece quando a organização se expõe mesmo com a falta de ações de gestão que reduzam a possibilidade de ocorrência e impacto. Segundo o Manual do Tribunal de Contas (TCU, 2014, p. 57):

$\mathrm{O}$ risco inerente pode ser conceituado como aquele intrínseco à atividade que está sendo realizada. Se o risco inerente estiver em um nível não aceitável para a organização, controles internos devem ser implementados pelos gestores para mitigar esses riscos.

$\mathrm{O}$ risco residual corresponde àquele que permanece mesmo após a implementação de ações para seu tratamento.

\section{METODOLOGIA}

A pesquisa de caráter qualitativo tem como objetivo central o estudo dos processos do setor refeitório do Campus do IFBAIANO em Teixeira de Freitas/BA.

O problema da pesquisa parte de dois eixos norteadores: a dificuldade do campus em operacionar de forma simples o mapeamento de processos nos setores, e a dificuldade dos discentes do Curso de Técnico em Administração em "visualizar" os processos, mesmo aqueles cotidianos do quais presenciavam diariamente, dificultando assim o entendimento e sua representação gráfica em forma de fluxograma.

O estudo foi pautou-se na seguinte questão norteadora: seria possível operacionalizar o mapeamento de processos em um setor do Campus Teixeira de Freitas de forma a colaborar com o ensino apresendizagem dos discentes?

A partir deste contexto e com as devidas autorizações da equipe gestora foi possível então iniciar o estudo. Trata-se de uma pesquisa qualitativa centrado nas atividades do setor refeitório subordinado hierarquicamente à Coordenação de Assistência Estudantil (CAE). Para a composição do mapeamento de seus processos foram utilizadas fontes bibliográficas, dados coletados em campo e informações fornecidas pela nutricionista responsável pelo setor Refeitório.

Foram consultados ainda documentos norteadores para alcançar o objeto de estudo, como o Plano de Desenvolvimento Institucional (PDI) e relatórios divulgados pelo Ministério da Educação (MEC).

Como resultados pode-se formular fluxogramas (representação gráfica dos fluxos dos processos setoriais) além de uma cartilha informativa que visa auxiliar os servidores em relação ao mapeamento de novos processos ou reformulação dos mesmos.

Quanto à pesquisa-ação, enquadra-se no tocante às intervenções (levantamento das dificuldades do setor com apoio da Nutricionista responsável e formulação dos fluxogramas para o mapeamento de processos). De acordo com Severino (2008, p. 120):

A pesquisa-ação é aquela que além de compreender, visa intervir na situação, com vistas a modifica-la. O conhecimento visado articula-se a uma finalidade intencional de alteração da situação pesquisada. Assim, ao mesmo tempo que 


\section{A IMPORTÂNCIA DO MAPEAMENTO DE PROCESSOS PARA O ENSINO E APRENDIZAGEM DOS ALUNOS DO CURSO TECNICO EM ADMINISTRAÇÃO DO IFBAIANO}

realiza um diagnóstico e a análise de uma determinada situação, a pesquisaação propõe ao conjunto de sujeitos envolvidos mudanças que levem a um aprimoramento das práticas analisadas.

Após a autorização da Direção, do setor CAE e da Nutricionista para prática do estudo, foi possível a realização de visitas, entrevistas e observações junto ao setor refeitório. As visitas foram semiestruturadas e tiveram seus apontamentos registrados em uma espécie de "diário de observação". Os serviços da CAE são direcionados à assistência a comunidade estudantil, além de pais e responsáveis, sendo disponibilizados atendimentos psicológicos, assistência social e nutricional e o fornecimento de cerca de 520 refeições diárias para todos os discentes.

Já as entrevistas para formulação dos fluxogramas foram previamente agendadas com a responsável pelo setor, seguindo metodologia específica (utilização de símbolos e setas) para formulação de fluxogramas setoriais.

Após o esboço dos fluxogramas (realizados com aporte das entrevistas) foi possível a formulação digital do conteúdo com auxílio do software Lucidchart. Lembrando que todas estas etapas foram orientadas pela docente responsável pela disciplina e tiveram autorizações das chefias setoriais uma vez que os resultados deste estudo auxiliaram no percentual de processos mapeados do Campus Teixeira de Freitas.

\section{RESULTADOS E DISCUSSÕES}

Deve-se destacar que esta pesquisa só pode ter êxito devido ao profissionalismo dos servidores envolvidos que prestaram informações e detalhes dos processos inerentes ao setor mesmo diante de diversas dificuldades.

Esse aspecto é importante para que o mapeamento de processo seja fidedigno e compatível com a realidade. Ao formular os fluxogramas muitas vezes os servidores podem ficar receiosos com a visibilidade de suas tarefas e desta forma podem negar informações, o que não é permitido de acordo com as normativas do Serviço Público Federal.

O setor do refeitório oferece para toda comunidade estudantil refeições nos períodos: manhã, tarde e noite de segunda a sexta-feira e aos sábados quando são dias letivos. Seu horário de funcionamento se inicia das $06 \mathrm{~h} 20 \mathrm{~min}$. da manhã e finaliza às 20:00h. Com isso é importante que o ambiente interno e instalações estejam compatíveis com os padrões de segurança, limpeza e conforto para que o serviço oferecido seja de qualidade tanto para os alunos quanto para os próprios colaboradores.

Com as visitas de observação foram notados alguns problemas na estrutura do local, principalmente em relação ao conforto térmico, janelas dentre outros aspectos. É válido salientar que os problemas encontrados nas instalações internas e externas do setor não competem a nutricionista responsável pelo mesmo, visto que são problemas de cunho estrutural, que necessitam de manutenção periodicamente para seu pleno funcionamento.

Apesar das adversidades como a redução drástica da equipe de terceirizados devido ao contingenciamento de verbas ocorrido em 2019, as atividades realizadas por toda a equipe se dão de modo satisfatório considerando estas limitações.

Os fluxogramas produzidos pela equipe de estudo abarcam processos relacionados aos procedimentos realizados pela nutricionista, dentre eles:

-Entrada e saída de alimentos e produtos destinados ao refeitório; 


\title{
A IMPORTÂNCIA DO MAPEAMENTO DE PROCESSOS PARA O ENSINO E APRENDIZAGEM DOS ALUNOS DO CURSO TÉCNICO EM ADMINISTRAÇÃO DO IFBAIANO
}

\author{
-Orientação nutricional; \\ -Pedido de alimentos aos fornecedores; \\ -Orientações para colaboradores do refeitório, \\ -Orientações sobre os procedimentos de higiene e limpeza; \\ -Avaliação do layout da cozinha do refeitório; \\ -Inspeção de maquinário; \\ -Organização de eventos; \\ -Planejamento de compras;
}

Ao término do estudo todos os fluxogramas foram revisados, a classificação dos riscos realizada pela docente (representante do NUPPI) e entregues impressos e no formato PDF (Portable Document Format -Formato Portátil de Documento) ao gestor da CAE e a Direção Geral para serem utilizados nos relatórios enviados à Reitoria. Foram mapeados $29,20 \%$ dos processos indicados pelos servidores da CAE.

Em relação ao ensino e aprendizagem dos discentes o estudo pode ser considerado como prática exitosa, contudo, inicialmente foi notada a dificuldade dos discentes se apropriarem dos conhecimentos teóricos necessários para que as entrevistas pudessem ser realizadas, e as informações coletas com objetividade. Esta etapa exige do pesquisador habilidade para realizar anotações das etapas que são relatadas pelo servidor responsável, desta forma foi sugerido que a equipe pudesse fazer as entrevista com a presença de dois ou três membros.
Os maiores problemas dessa geração são relacionados à interação social. Paradoxalmente, por estarem tão conectados virtualmente, muitos deles sofrem com a falta de intimidade com a comunicação verbal, o que acaba por causar diversos problemas com as outras gerações. Segundo alguns analistas, essa Geração também é marcada pela ausência da capacidade de ser ouvinte. (MEYER, 2019, n.p).

Destaca-se inclusive que o perfil do curso técnico em adminisitração do IFBAIANO vislumbra formar:

\footnotetext{
O profissinal formado no Curso Técnico em Administração na Forma integrada do IFBAIANO deve ter visaão sistêmica das organizações, de forma que possa aplciar as técnicas e ferramentas para auxiliar no processo de gestão das intituições públicas, privadas e do terceiro setor. Devem estar aptos a atuar de forma proativa em situações novaas e em contínua mutação como é o caso das intituições públicas, privas e do terceiro setor contemporâneas. . (BRASIL, PPC, 2016, p.16).
}

Um fator interessante neste estudo é a "impaciência" que os discentes apresentaram quando se deparam com processos que pensavam sem "básicos" e "simples" e que após observarem todas as atividades nele contidas puderam perceber a complexidade. Outro aspecto salientado foram as etapas burocráticas de atividades que poderiam ser otimizadas por meio de sistemas informacionais e retirada dos "gargalos", como são conhecidos os empecilhos que podem tornar menos eficiente ou até não concluídas atividades e processos. 


\section{A IMPORTÂNCIA DO MAPEAMENTO DE PROCESSOS PARA O ENSINO E APRENDIZAGEM DOS ALUNOS DO CURSO TECNICO EM ADMINISTRAÇÃO DO IFBAIANO}

É natural que a princípio sejam listadas muitas atividades que posteriormente se conectam ou fazem parte de outro processo, devido a este aspecto foi realizado o esboço "no papel" e posteriormente pode-se "transferir" para o computador com o auxílio do software Lucidchart, como pode ser observado na figura 02 a seguir:

Figura 02- Fluxograma do processo "controle de estoque".

CONTROLE DE ESTOQUE (SAÍDA DO ESTOQUE PARA CONSUMO DE PRODUTOS NO REFEITÓRIO)

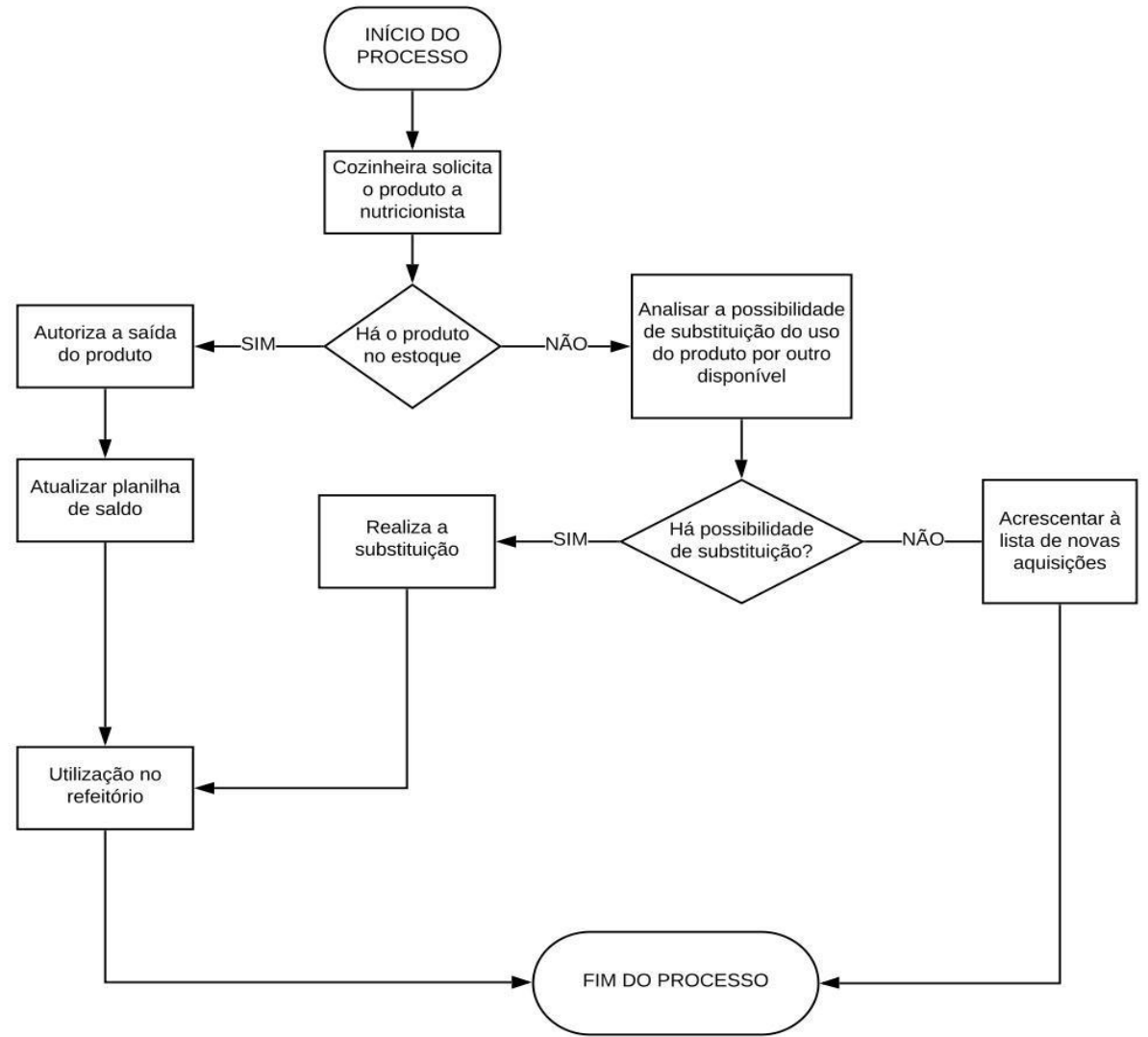

Fonte: Equipe de pesquisa, 2019.

O conteúdo teórico do estudo foi composto pela parte documental de leis, decretos e documentos institucionais e parte gráfica simbólica para construção de fluxogramas. Desta forma exige que o docente formule material didático de apoio e planeje o conteúdo das aulas de para que possa dar assistência aos discente até o alcance dos objetivos propostos no estudo. Que neste caso foi o mapeamento dos processos do setor refeitório e a formulação gráfica de seus processos por meio de fluxogramas.

\section{CONSIDERAÇÕES FINAIS}

Ao término dos estudos e coletas e informações pode-se inferir que em termos práticos, o entendimento das metodologias precisa considerar a disponibilidade de tempo dos servidores e seu conhecimento acerca das etapas contínuas do mapeamento e classificação dos riscos, o que requer capacitação contínua e principalmente abertura 


\section{A IMPORTÂNCIA DO MAPEAMENTO DE PROCESSOS PARA O ENSINO E APRENDIZAGEM DOS ALUNOS DO CURSO TÉCNICO EM ADMINISTRAÇÃO DO IFBAIANO}

para o diálogo.

Nesse contexto, a Direção do Campus, a CAE e a nutricionista responsável pelo refeitório apoiaram todas as iniciativas para o avanço dos trabalhos, estando sempre atentos aos encaminhamentos, ponto este essencial para o desenvolvimento da Governança Corporativa.

Outro fator importante refere-se à necessidade do setor de comunicação concretizar a melhoria do material instrucional que foi desenvolvido pelo NUPPI para informar os servidores sobre a importância do mapeamento de processos, as normativas relacionadas e o contexto da Governança Corporativa no Serviço Público Federal.

É essencial a adequação de material instrucional para que os servidores possam consultar periodicamente, além de informar os novos servidores que chegam para trabalhar nos setores, considerando que os processos podem mudar e seus fluxogramas precisarão ser alterados seja por modificações em sistemas computacionais, softwares ou na forma de execução das atividades cotidianas.

A percepção dos discentes a cerca dos processos estudados indicou que como usuários do refeitório as atividades pareciam mais "fáceis" de serem realizadas, desta forma a comunidade estudantil de forma geral ao reclamar da fila ou de algum outra situação relacionada ao refeitório não vislumbra a complexidade de tarefas que são diariamente realizadas para que uma refeição chegue até a mesa para o consumo. Vislumbrando os processos da forma que realmente acontecem é possível elencar etapas, sugerir melhorias e consequentemente alcançar maior eficiência.

Percebe-se que a questão norteadora indicada na problematização da pesquisa pode ser analisada, visto que foi possível inserir a prática do mapeamento de processos de um setor do Campus Teixeira de Freitas no contexto de ensino aprendizagem dos discentes do Curso de Administração (participantes do estudo).

Neste sentido, a colaboração dos discentes do Curso Técnico Integrado em Administração configura-se como prática importante para a rotina dos futuros técnicos em Administração e para as organizações em que estarão inseridos no mercado de trabalho.

\section{REFERÊNCIAS}

ABNT. Associação Brasileira de Normas técnicas, ABNT NBR ISO 31000:2018: Gestão de Riscos - Diretrizes. Disponível em: $<$ http://www.abnt.org.br/noticias/5827abnt-nbr-iso-31000-gestao-de-riscos-diretrizes>. Acesso em: 16 de set. 2018.

ALONÇO, Guilherme. O que é fluxogramas de processos? Disponível em: https:/certificacaoiso.com.br/o-que-e-fluxograma-de-processos/. Acesso em: 21 de out. de 2019.

ALMEIDA, Vinícius. O que é e como fazer Mapeamento de Processos em 6 passos. Disponível em $<$ https://www.euax.com.br/2016/06/como-fazer- mapeamento-deprocessos-em-6-passos/>. Acesso em: 04 de set. de 2019.

ANDRADE, Elzimar. Gerenciamento de processos para melhoria da eficiência na administração pública: estrutura de referência para a UTFPR. Disponível em: http://repositorio.utfpr.edu.br/jspui/bitstream/1/2565/1/CT_PPGPGP_M_Andrad e\%2C\%20Elzimar_2017.pdf. Acesso em: 6 de nov. de 2019. 


\section{A IMPORTÂNCIA DO MAPEAMENTO DE PROCESSOS PARA O ENSINO E APRENDIZAGEM DOS ALUNOS DO CURSO TECNICO EM ADMINISTRAÇÃO DO IFBAIANO}

BAUM, Eder. Conceitos básicos de atividades, tarefas, processos e macroprocesso. Disponível em: https://www.sabesim.com.br/conceitos- atividades-tarefas-processosmacroprocesso/. Acesso em 5 de nov. de 2019

BARROSO, Roberto Luís. Ética e jeitinho brasileiro: por que a gente é assim? Brazil Conference at Harvard \& MIT. Nonprofit Organization Management, EUA, 2017. Disponível em: 〈https://www.conjur.com.br/dl/palestra-barroso-jeitinho-brasileiro.pdf> Acesso em: 20 de dez.2020.

BRASIL. IFBAIANO. Projeto Pedagógico do Curso Técnico Integrado em Administração -PPC, 2016. Disponível em: $<$ https://www.ifbaiano.edu.br/unidades/teixeira/files/2018/04/PPC-Curso-TecnicoIntegrado-Administra\%C3\%A7\%C3\%A3o.pdf>. Acesso em: 05 de abr. 2020.

BRASIL.IFBAIANO. Carta de Serviços ao Cidadão. Disponível em: <http://IF BAIANO.edu.br/portal/wp-content/uploads/2015/12/carta-de-servicos-ao-cidadao-ifbaiano-atualizado-23-de-fevereiro-de-2017.pdf>. Acesso em: 17 de set. 2019.

BRASIL IFBAIANO. Estatuto do Instituto Federal de Educação, Ciência e Tecnologia Baiano. Disponível em: $<$ http://IF BAIANO.edu.br/portal/wpcontent/uploads/2017/03/ESTATUTO-DO-IF-BAIANO-revisado-PARA-

IMPRESS\%C3\%83O.pdf>. Acesso em: 17 de set. 2019.

BRASIL. Plano de Desenvolvimento Institucional 2015-2019/IF BAIANO. $<$ Disponível em: http://IFBAIANO.edu.br/portal/wp-content/uploads/2015/12/pdi2015-2019-versao-2018.pdf>. Acesso em: 17 de set. 2018.

BRASIL IFBAIANO. Regimento Geral IF BAIANO. Disponível em: http://IF BAIANO.edu.br/portal/wp-content/uploads/2015/12/Regimento-Geral.pdf. Acesso em: 17 de set. 2019.

BRASIL. MINISTÉRIO DO PLANEJAMENTO, ORÇAMENTO E GESTÃO (MPOG). Secretaria de Gestão Pública. Departamento de Inovação e Melhoria da Gestão. Gerência do Programa GesPública. Guia de Orientação para o Gerenciamento de Riscos, versão 1.0, Brasília, mar. 2013.

BRASIL. MINISTÉRIO DO PLANEJAMENTO, ORÇAMENTO E GESTÃO (MOPG) e CONTROLADORIA-GERAL DA UNIÃO(CGU). Instrução Normativa Conjunta n. ${ }^{\circ 001}$-dispõe sobre controles internos, gestão de riscos e governança no âmbito do Poder Executivo Federal. Brasília, mai. 2016.

BRASIL. MINISTÉRIO DO PLANEJAMENTO, DESENVOLVIMENTOE GESTÃO (MPOG). Portaria MP no 426, de 30 de dezembro de 2016. Dispõe sobre a instituição da Política de Gestão de Integridade, Riscos e Controles Internos da Gestão do Ministério do Planejamento, Desenvolvimento e Gestão. Disponível em:

$<$ https://www.diariodasleis.com.br/legislacao/federal/exibe_artigo.php?ifl=235066>.

Acesso em: 09 de jan. 2017. 


\section{A IMPORTÂNCIA DO MAPEAMENTO DE PROCESSOS PARA O ENSINO E APRENDIZAGEM DOS ALUNOS DO CURSO TÉCNICO EM ADMINISTRAÇÃO DO IFBAIANO}

BRASIL. Ministério do Planejamento, Orçamento e Gestão. Programa Gespública. Brasília: MP, $\quad 2015 . \quad$ SEGEP, Disponível em: http://www.gespublica.gov.br/sites/default/files/documentos/gagp250_pontos_novo.pdf. Acesso em: 16 de dez. 2020.

BRASIL. Tribunal de Contas da União. TCU. Referencial Básico de Governança Aplicável a Órgãos e Entidades da Administração Pública e Ações Indutoras de Melhoria. Disponível em: $<$ http://www.fazenda.gov.br/pmimf/institucional/downloadde-arquivos/governanca-publica-tcu.pdf. Tribunal de Contas da União>. Brasília: TCU, Secretaria de Planejamento, Governança e Gestão, 2014. Acesso em: 16 de mai. 2018.

BRASIL. Tribunal de Contas da União. Referencial básico de governança aplicável a órgãos e entidades da administração pública. Tribunal de Contas da União. Versão 2 - Brasília: TCU, Secretaria de Planejamento, Governança e Gestão, 2014. 80 p. Disponível em: https://portal.tcu.gov.br/data/files/E8/14/13/3D/43B0F410E827A0F42A2818A8/266378 8.PDF. Acesso em: $10 \mathrm{de}$ dez. 2020.

BRASIL. Tribunal de Contas da União. 10 passos para a boa gestão de riscos.Tribunal de Contas da União. - Brasília : TCU, Secretaria de Métodos e Suporte ao Controle Externo (SEMEC), 2018. 31 p. Disponível em: <file:///C:/Users/Windows\%207/Downloads/10\%20Passos\%20para\%20a\%20Gestao\%2 0de\%20Riscos\%20-\%20Web.pdf>. Acesso em: 20 de dez.2020.

COSO ERM. Gerenciamento de Riscos Corporativos - Estrutura Integrada, 2004.

COSO. Gerenciamento de Riscos Corporativos - Estrutura Integrada. Tradução: Instituto dos Auditores Internos do Brasil (Audibra) e Pricewaterhouse Coopers Governance, Risk and Compliance, Estados Unidos da América, 2007.

DUBRIN, Andrew J. Fundamentos do comportamento. Trad. James Sunderland Cook, Martha Malvezzi. São Paulo: Pionera Thomson Learning, 2003.471p.

ENAP. Escola Nacional de Administração Pública. Introdução à Gestão de Riscos: estruturas de gerenciamento e bases normativas. Módulo 1, Brasília: 2018a, 16p. [pdf].

ENAP. Escola Nacional de Administração Pública. Implantando a Gestão de Riscos no setor público: estrutura do COSO ERM. Módulo 2, Brasília:2018b, 14p. [pdf].

ENAP. Escola Nacional de Administração Pública. Ciclo de Gerenciamento de Riscos Corporativos. Módulo 3, Brasília: 2018v, 26p. [pdf].

LAGE JÚNIOR, Murís. Mapeamento de processos de Gestão empresarial. Curitiba: Intersaberes, 2017.175p.

MENEZES, Wilson Ferreira. Escolha e decisão em situação de incerteza e risco. Revista eletrônica Nexus Econômicos, p. 59-106, vol. V - no 9 - dezembro de 2011 CME-Universidade Federal da Bahia, UFBA . Disponível 


\section{A IMPORTÂNCIA DO MAPEAMENTO DE PROCESSOS PARA O ENSINO E APRENDIZAGEM DOS ALUNOS DO CURSO TECNICO EM ADMINISTRAÇÃO DO IFBAIANO}

em:〈https://periodicos.ufba.br/index.php/revnexeco/article/view/6769/4630>. Acesso em: 18 de dez.2020.

MEYER, Maximiliano. Quais as diferenças entre as gerações $X, Y$ e $Z$ e como administrar os conflitos,2019. Disponível em: $<$ https://www.oficinadanet.com.br/post/13498-quais-as-diferencas-entre-as-geracoes-xy-e-z-e-como-administrar-os-conflitos>. Acesso em 12 de fev. 2020).

OLIVEIRA, Djalma de P. R. de. Sistemas, organização \& métodos: uma abordagem gerencial. 17 ed. São Paulo: Editora Atlas, 2007. 480p.

PARDINI, Eduardo. Estrutura do COSO na gestão de riscos, 2017. Disponível em:< https://administradores.com.br/artigos/estrutura-do-coso-na-gestao-de-riscos $>$. Acesso em 21 de dez. 2020.

RIBEIRO, Roberto et al. O gerenciamento de processos, atividades e tarefas através do uso de indicadores de desempenho: um estudo de caso em um incubatório de ovos. Disponível em: $<$ https://anaiscbc.emnuvens.com.br/anais/article/viewFile/876/876>.Acesso em 20 de nov. de 2019.

SEVERINO, Antônio J. Metodologia do trabalho científico. 23.ed. São Paulo: Cortez, 2008. 